Original article

\title{
Comparison of anthropometric parameters among Iranian and Spanish water polo players
}

\author{
Pooya Nekooei ${ }^{1}$, Sara Majlesi ${ }^{2}$, Gholamreza Sharifi ${ }^{3}$, Tengku Fadilah Tengku Kamalden ${ }^{1}$, Paria Nekouei ${ }^{4}$ \\ ${ }^{1}$ University Putra Malaysia, Selangor, Malaysia \\ ${ }^{2}$ University Malaya, Kuala Lumpur, Malaysia \\ ${ }^{3}$ Islamic Azad University, Isfahan, Iran \\ ${ }^{4}$ University of Isfahan, Isfahan, Iran
}

Received 1 December 2015, Revised 8 January 2016, Accepted 21 January 2016

(c) 2015, Nekooei P., Majlesi S., Sharifi G., Fadilah T., Nekouei P.

(C) 2015, Russian Open Medical Journal

Abstract: The purpose of this study was to compare the anthropometric parameters between Iranian and Spanish water polo national team players.

Material and Methods - The research was conducted in the physiological laboratory of Isfahan Azad University. Participants who participate in this study were 44 male national water polo players ( 22 Iranian and 22 Spanish), age $22 \pm 2$ years old (Mean \pm SD). For the aim of this study twenty anthropometric parameters that was more important for water polo was measured and analysis. All the parameters were measured base on the international standard of anthropometric parameters (International Society for the Advancement of Kinanthropometry - ISAK). For analysis data, normal distribution of the data was proved by Kolmogorov-Smirnov test and then comparison between two groups was done by $t$-test.

Results - The results showed a significant difference in seven anthropometric parameters contain body fat percentage $(P=0.031)$, biliocristal breadth $(P<0.001)$, wrist breadth $(P<0.001)$, chest girth $(P=0.021)$, mid-thigh girth $(P=0.019)$, palm length $(P<0.001)$ and height $(P=0.032)$.

Conclusion - Spanish players with relatively higher underlying levels of anthropometric parameters compare to Iranian water polo players had stronger ability to control the ball with the bigger palm and bigger wrist breadth, also they had stronger ability to do water vertical jump, cause of higher value of biliocristal breadth and mid-thigh girth and also stronger throwing the ball because of bigger muscle on their chest part of their body. However, Base on this study, having longer hands, more muscular body than fat and taller stature is an advantage for the players because it is considered to be a useful parameter in water polo.

Keywords: anthropometry, national player, water polo.

Cite as Nekooei P, Majlesi S, Sharifi G, Fadilah T, Nekouei P. Comparison of anthropometric parameters among Iranian and Spanish water polo players. Russian Open Medical Journal 2016; 5: e0204.

Correspondence to Pooya Nekooei. Tel: +60-142202790. E-mail: pooya.nekooei@gmail.com

\section{Introduction}

The phenomenon of gradual and continuous evolution of human being is highly subject to various vicissitudes during life. Specific capabilities and limitations are inherent in each period of evolution and each period has its own specific demands [1]. Knowledge of human growth and development in addition to physical and physiology differences of the human body help us better understand these periods and learn how to improve this evolutionary process. Recently, several specific anthropometric methods and techniques have been developed and they have undergone their evolutionary processes [2]. Since on one hand competitive sports require athletic, prepared and special body of each specific field of sport, and on the other hand it is possible to measure success and victory by the score, record and also time, fitness experts and professional trainers have a keen interest in physical and physiological characteristics of the athletes in order to determine the factors affecting the athletes' success [3]. What they aim at is devising different training and implementing methods to avoid the negative impact of the disruptive elements and to foster the impact of the positive ones.
In the present study, anthropometric parameters of the players of one of the world's top teams i.e. Spain will be compared to those of Iranian players in the field of water polo because several factors such as age, gender, physical structure of human body (stature, weight, length of the body organs, etc.), body composition (the average percent of body fat), fitness and many other factors are involved in displaying the motor and physical skills and abilities of the athletes. The aim of this comparison is because the Spanish water polo team is in top three water polo team in the world but notwithstanding of having the best equipment, standard swimming pool and hiring top ranked water polo coach in Iran but Iranian water polo team is not improving in their ranking yet. Identifying and the explaining the amount of the effect of each variable forms a subject for new investigations. The experts and the trainers in physical education and sports science are seeking the positive and negative effects of the factors mentioned above in order to achieve better records and implement top skills of the athletes. They try to improve physical performance and achieve success by removing negative variables and reinforcing the positive ones. As an instance, it is a must for a 
high jump athlete to be taller than the other athletes [4]. Over and above that, less weight is considered a positive characteristic in this field of sport [5]. In addition, swimmers ought to have more subcutaneous fat than the other athletes. Therefore, having a certain percentage of body fat is useful for swimmers and it raises the quality of their skill implementation [6, 7].

Through the complex interaction of several factors, including physical, physiological, psychological and technical, a good performance is emerged [5, 8]. Therefore, having a program which is ideally planned and organized for discovering, nurturing and maintaining the talent, is essential to the successful development in each sport field [9]. After participating in a training program, some of the participants make progress due to their individual differences while the other participants either do not progress at all or their progress is not so significant. So, according to $[10,11]$. Special needs and demands of each specific sport and also the individuals' ability must be taken into account when designing the training programs. As a matter of fact, what we know as talent is a degree of the main physical, physiological or intellectual characteristics of the athletes which may somehow contribute in their performance [12-14] believe that since both biological and behavioral scientists have represented a strong genetic influence on sports performance, an appropriate talent in each sport field is a factor of great importance in the successful performance in that field.

Many of the talent agencies are focused on anthropometric variables since the structural characteristics of the individuals cannot be easily modified $[15,16]$. In some sport fields, given the diversity of the skills in that field, physical characteristics of the players play a significant role in developing the team's technical and tactical training program. To give an example, because of having various trends and necessarily several different types which are similar to their fields of sport (such as swimming, handball), and since it is played in water, the water polo players must have some differences in their anthropometric parameters compared to the players of other sports. These differences are measurable in the following anthropometric structures: body fat percentage, body mass index (BMI), wrist breadth, biacromial breadth, biliocristal breadth, waist girth, chest girth, wrist girth, forearm girth, arm flexed girth, arm girth, ankle girth, calf girth, mid-thigh girth, superior thigh girth, gluteal girth, arm spam, hand length, weight and stature are the variables which are investigated in this study. It explains why there are marked individual differences in the physiological and anthropometric parameters of Iranian water polo players, and those of the other countries. In previous studies no comparison has been made between the anthropometric parameters of Iranian players and the players of other countries in the field of water polo. The previous research has entirely focused on the anthropometric parameters and their influence on the anthropometric parameters' severity and change during the racing season.

Therefore, the main purpose of the present study is comparing the players' anthropometric parameters in Iran national water polo team with those of the Spain national team and dealing with the existing differences.

\section{Material and Methods}

Given the research topic which is comparing the anthropometric parameters between the two water polo national teams, the present study is descriptive, analytical and comparative. The participants included 22 Iranian men water polo players being either a member of the national team in 2014 or having a minimum of 4-year membership experience with the age range of $18-25$ at previous 5 years.

Anthropometric parameters of the Iranian players were compared with their Spanish Counterparts which have been recorded previously in literature review journals.

Based on the topic of research the raw data, including the anthropometric sizes of the Iranian national team players, was gathered through direct measurement according to the international standards of anthropometric parameters (International Society for the Advancement of Kinanthropometry ISAK) at Physical Education Laboratory of the Khorasgan Islamic Azad University in 2014. It was measured for three time with time intervals at 9 a.m. by the researcher himself and the research team under the supervision of the anthropometric specialist. The data was recorded in the check lists which have been prepared before. Meanwhile, a written consent was obtained from all the participants of the study and all the testing procedures were explained to them. The data related to the Spanish national team was gathered through the study of its literature review [17].

Procedures were performed in accordance with the Helsinki Declaration for the ethical treatment of human participants [18]. Ethical approval for the study was obtained from the Federation of swimming, Department of Human Resources, in Malaysia. The subjects were given a clear explanation of the objectives of the study, as well as the potential risks involved, and consent forms were obtained for all subjects [19].

In the present research, all the anthropometric parameters of Iranian players were evaluated by descriptive statistics (number of samples, mean, median, mode, and standard deviation). Because the few people subject were included to our study, before start analysis the data by t-test, it was measured the normality distribution of the data's by Kolmogorov-Smirnov test. p-level was higher than 0.05 for all variables, so while all the data's was normal then the mean values of the anthropometric parameters of Iranian and Spanish players were compared through a univariate ttest and significant amounts were calculated and recorded.

\section{Results}

The following Table 1 is an overview of all 20-set anthropometric parameters. Using a univariate $t$-formula, the mean values of the Iranian players were compared with those of the Spanish players which have been recorded previously (literature review). In this study, the significant probability of all numbers is obtained through a univariate t-test and it is less than 0.05 and also all the theories and values have been obtained with $95 \%$ certainty. The KolmogorovSmirnov normality test was done, and it shows that all data are normal and t-test can be used for analyses these variables. The results of the normal distribution are showed in Table 1.

Concisely, from among 20 anthropometric parameters of Iranian and Spanish players, only 7 of the anthropometric parameters such as subcutaneous fat, biliocristal breadth, wrist breadth, chest girth, midthigh girth, hand length and stature was $p<0.05$ and count as significant difference between groups and the other 13 parameters did not show any significant between two groups. From among those 7 parameters, the amount of subcutaneous fat was higher in Iranian players than the Spanish, but the values of the other six parameters were higher in the Spanish players compared to those of the Iranians. As well as the weight of players with $p=0.084$ was not significant but it showed that the weight of players also has slightly different but the different was not significant. 
Table 1. Overview of all 20-set anthropometric parameters

\begin{tabular}{|c|c|c|c|c|c|c|c|}
\hline Variables & Country & Number & Mean & $T$-value & $S D$ & $P$ & Kolmogorov-Smirnov \\
\hline \multirow{2}{*}{ Body fat, $\%$} & Iranian & \multirow{2}{*}{22} & 12.85 & \multirow{2}{*}{2.48} & 3.10 & \multirow{2}{*}{0.031} & 0.200 \\
\hline & Spanish & & 10.63 & & & & \\
\hline \multirow{2}{*}{ Biliocristal breadth, mm } & Iranian & \multirow{2}{*}{22} & 295.45 & \multirow{2}{*}{-15.27} & 13.56 & \multirow{2}{*}{$<0.001$} & 0.082 \\
\hline & Spanish & & 355.20 & & & & \\
\hline \multirow{2}{*}{ Wrist breadth, $\mathrm{cm}$} & Iranian & \multirow{2}{*}{22} & 55.63 & \multirow{2}{*}{-7.49} & 2.59 & \multirow{2}{*}{$<0.001$} & 0.200 \\
\hline & Spanish & & 61.20 & & & & \\
\hline \multirow{2}{*}{ Chest girth, $\mathrm{cm}$} & Iranian & \multirow{2}{*}{22} & 102.18 & \multirow{2}{*}{-2.70} & 5.03 & \multirow{2}{*}{0.021} & 0.155 \\
\hline & Spanish & & 106.10 & & & & \\
\hline \multirow{2}{*}{ Mid-thigh girth, cm } & Iranian & \multirow{2}{*}{22} & 54.52 & \multirow{2}{*}{-2.75} & 2.52 & \multirow{2}{*}{0.019} & 0.200 \\
\hline & Spanish & & 56.52 & & & & \\
\hline \multirow{2}{*}{ Palm length, mm } & Iranian & \multirow{2}{*}{22} & 197.16 & \multirow{2}{*}{-7.00} & 7.34 & \multirow{2}{*}{$<0.001$} & 0.200 \\
\hline & Spanish & & 212.00 & & & & \\
\hline \multirow{2}{*}{ Stature, $\mathrm{cm}$} & Iranian & 22 & 184.01 & $2 \wedge 6$ & 4.81 & 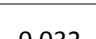 & 0.200 \\
\hline & Spanish & 22 & 187.41 & -2.46 & & 0.032 & \\
\hline $\mathrm{BMI} \mathrm{kg} / \mathrm{m}^{2}$ & Iranian & 22 & 25.30 & -00 & 2.27 & 0930 & 0.200 \\
\hline & Spanish & 22 & 25.36 & -0.09 & & 0.930 & \\
\hline & Iranian & & 441.06 & & 20.74 & & 0.200 \\
\hline Biacromial breadth, mm & Spanish & 22 & 445.80 & -0.79 & & 0.445 & \\
\hline Wrict rirth $\mathrm{sm}$ & Iranian & 27 & 17.77 & 070 & 0.78 & 0100 & 0.200 \\
\hline Vurist girth, cm & Spanish & 22 & 17.61 & 0.10 & & 0.499 & \\
\hline & Iranian & & 29.08 & & 1.33 & & 0.200 \\
\hline Forearm girth, cm & Spanish & 22 & 29.54 & -1.19 & & 0.259 & \\
\hline Arm girth $\mathrm{cm}$ & Iranian & 22 & 33.85 & -125 & 2.75 & 0.276 & 0.200 \\
\hline & Spanish & 22 & 34.76 & -1.25 & & 0.276 & \\
\hline & Iranian & & 36.49 & & 2.82 & 0236 & 0.200 \\
\hline Tense arm girth, cm & Spanish & 22 & 37.31 & -1.01 & & 0336 & \\
\hline Whict rirth $\mathrm{sm}$ & Iranian & 22 & 88.75 & 1196 & 5.45 & 0172 & 0.200 \\
\hline valst girtn, cm & Spanish & 22 & 86.46 & 1.40 & & $0.1 / 3$ & \\
\hline & Iranian & & 98.88 & & 4.66 & & 0.074 \\
\hline Hip girth, cm & Spanish & 22 & 100.92 & -1.52 & & 0.158 & \\
\hline & Iranian & 22 & 59.99 & 17 & 3.80 & & 0.200 \\
\hline Superior tight girth, cm & Spanish & 22 & 60.01 & -0.17 & & 0.987 & \\
\hline & Iranian & 22 & 37.94 & 047 & 2.09 & 0684 & 0.064 \\
\hline Calf girth, cm & Spanish & 22 & 37.69 & 0.42 & & 0.684 & \\
\hline & Iranian & & 23.33 & & 1.23 & & 0.200 \\
\hline Ankle girth, cm & Spanish & 22 & 23.32 & 0.04 & & 0.965 & \\
\hline & Iranian & 22 & 195.55 & & 5.17 & & 0.200 \\
\hline Arm spam, cm & Spanish & 22 & 195.08 & 0.32 & & 0.755 & \\
\hline & Iranian & & 85.26 & & 7.23 & & 0.186 \\
\hline Weight, kg & Spanish & 22 & 89.24 & -1.90 & & 0.084 & \\
\hline
\end{tabular}

BMI, body mass index.

\section{Discussion}

The obtained data clearly indicated the existence of a difference in the anthropometric parameters between the Spanish and the Iranian players. This section will attempt to discuss and compare the anthropometric parameters of the Iranian national team and the research which has been carried out before on the Spanish national team in the 20 parameters mentioned earlier.

The parameters in which significant differences were observed between the players of the two teams include the followings: subcutaneous fat, biliocristal breadth, wrist breadth, chest girth, mid-thigh girth, handlength and stature, and the parameters in which no significant difference was observed between the players of the two teams include the followings: body mass index (BMI), biacromial breadth, wrist girth, forearm girth, arm girth, arm flexed girth, waist girth, gluteus girth, superior thigh girth, calf girth, ankle girth, arm spam and weight.

Based on the performed statistical analysis, the mean values of skin fold fat were $10.63 \%$ and $12.85 \%$ for the Spanish [17] and Iranian players respectively. This measurement is an indication of a significant difference between the players of two teams in terms of the amount of subcutaneous fat. The fat percentage of Spanish players are similar and the same parameter value of Iranian are higher than previous published [20] however the fat percentage of Iranian players are similar with published [21-23]. Comparing these values suggests that Iranian players' total subcutaneous fat is higher than their international peers. However, after performing the statistical analysis and comparison between the Iranian and the Spanish players, no significant difference was detected in weight parameter. The mean weight value for the Iranians was $85.3 \mathrm{~kg}$ and it was $89.2 \mathrm{~kg}$ [17] for the Spanish which do not differ greatly. The weight value of both players was in line with previous published article [24], also in other research the researcher published the same value of weight for water polo players as published in this study $[1,25]$. As the Iranian players have more subcutaneous fat, it can be concluded that the Spanish players have more muscular bodies compared to the Iranians. This variable may have possibly been effective in their power movements. In addition, the Spanish are taller than the Iranian players. The mean value of stature for the Iranian was $184.0 \mathrm{~cm}$ 
while it was 187.4 for the Spanish. In the year 1998, Smith [26] described that national Greek team has mean height of $184.2 \mathrm{~cm}$ and also in 2004 Lozovina et al reported the statured of $189.5 \mathrm{~cm}$ for 65 water polo players from the top Croatian clubs [1]. So the valued who reported in other published showed that the stature value of Iranian team are in line with the national Greek team [26]. As all fitness experts know, taller height and a more or less heavy body is the most important factors for athlete's performance [20]. Therefore, it can be concluded that despite of that two groups weight are equal and more subcutaneous fat is in Iranian players as well as higher stature of the Spanish, in contrast to the Iranians, the Spanish players have more muscular bodies, taller stature and lower fat percentage which is an advantage for them. As a matter of fact, more muscular strength plays a significant role in players' hand speed, their fast and explosive movements, and also they can throw the ball faster [5] in the other hand wilmore reported that Smaller body density due to the larger body fat content is an advantage in water sports [27]. Moreover, in the study carried out on Hungarian water polo players by [1], it was concluded that the amount of fat in the body is positively correlated with the amount of the player's progress which is consistent with the findings of the present study.

The comparison between body mass index of Iranian players and that of the Spanish national team players pointed out that, no significant difference existed between two teams. While its mean value for the Iranians was 25.30 , it was 25.36 , being measured previously, for the Spanish [17]. It can be inferred that the difference in the Spanish players' performance compared to the performance of the Iranian players cannot be explained in terms of the difference in mean BMI but both team BMI are higher than the other value published $[1,28]$. Despite the fact that the Spanish have less subcutaneous fat than the Iranians, there is no significant difference between their BMI. Since no significant difference was observed in terms of weight, this can be accounted for by the fact that the Spanish players have more lean mass compared to the Iranian players. Based on the study in Spain concluded that there was a positive relationship between the body mass and the individual skill level and also the speed of the player shots to the goal in the present study, no significant difference was detected in this regard between the Iranian players and the Spanish players who play in one of the best teams of the world [17].

After doing research and detailed measurements of three organs (biliocristal breadth, biacromial breadth, and wrist breadth) significant differences were identified in only 2 parts, and in the remaining one organ no significant difference was observed. In two organs i.e. biliocristal and wrist breadth, the Spanish players had higher values than the Iranians. The average biliocristal breadth of Iranian and Spanish players are $295.5 \mathrm{~mm}$ and $355.2 \mathrm{~mm}$ respectively [17]. The biliocristal value of Iranian players was in line with the previous published [1] and same value for Spanish players was higher than previous published. The average wrist Breadth for the Iranians is $55.6 \mathrm{~mm}$ while it is $61.2 \mathrm{~mm}$ for the Spanish [17] indicating less value of Iranian wrist breadth compared to that of the Spanish. It can be claimed that because of Spanish players having larger biliocristal, must have greater waist and biliocristal girth but they do not. As a result, having equal waist girth, biliocristal girth, and weights, indicates the fact that Iranian players have more fat in their abdominal areas which is not a desirable valuable for the water polo players. It can also be said that, although Spanish players' wrists are wider than the Iranians', both groups have equal wrist girth as the Iranians have a higher percentage of fat $[2,8,17]$. Concluded that the Spanish players' wider wrists help them apply more force when swimming and have a greater tolerance in front of the shots. The wrist breadth is negatively related to speed and power of the swimmers [29]. These results are inconsistent with the findings of the present study.

In addition, compared to the Spanish players, in chest girth and mid-thigh girth some differences were detected in Iranians. The main reason accounting for bigger and stronger quadriceps and scapula seems to be the Spanish players' higher means in the two parameters mentioned compared with the Iranians. The ones which are two of the main parameters in water polo, because of being the only area holding the swimmer vertically in the surface of the water, having strong quadriceps when playing water polo is an advantage for players. Furthermore, the players need to do the eggbeater kick very quickly and powerfully in order to bring up their body out of the water $[30,31]$. Furthermore, a higher chest girth is an indication of a stronger scapula which is important in playing water polo as water polo players need to have stronger upper bodies in order to shoot, swim and get engaged with the other players [32].

After measuring the arm spam, the hand length and the stature of the Iranian players and comparing them with those of Spanish players, significant differences were detected in the mean values of hand length and stature of the two groups. The hand length mean for the Iranian was $197 \mathrm{~mm}$ while it was $212 \mathrm{~mm}$ for the Spanish. Hand length of Spanish players was in line with Croatian water polo players in 1980 and was greater than Croatian water polo players in 1995 [1], while the value for Iranian players was lower from Croatian water polo players in both years 1980 and 1995. A longer hand helps the Spanish in faster swimming and better controlling the ball. The Spanish players have an advantage over the Iranians since the water polo sport is played in water and most parts of the body are under water except passing, shooting and controlling the ball are all done by hand and therefore, having the longer hands is an important parameter for players. However, having longer hands and stature is an advantage for the players because it is considered to be a useful parameter in water polo [20]. Longer hands will help the players swim faster in speedy swimming and also perform faster shots. In this study, the difference between the stature and hand length is more in Iranian players than the Spanish.

\section{Conclusion}

The main purpose of the present study was to compare the anthropometric parameters of the Iranian and Spanish players. The results of the study indicated significant differences in 7 of the measured parameters (subcutaneous fat, biliocristal breadth, wrist breadth, chest girth, mid-thigh girth, hand length and stature) in players of two groups. In overall the result of this study indicate that professional water polo players from Spanish national team have some anthropometric difference toward to Iranian players so base on this study can be concluding that the water polo players who have taller statured, wider shoulder, hip and wrist, greater mid-thigh girth, longer hand and also less subcutaneous fat than others are the best water polo players.

\section{Practical suggestions}

1) After a brief look at the measured means and realizing the differences noted in this study, some constructive strategies can 
be considered for improving the performance of the Iranian national team players. Knowing these apparent differences and promoting awareness among this field's educators, physical education supervisors can be very helpful in achieving the desired objectives. In fact, knowing the shortcomings and weaknesses of the players, the physical education coaches can focus on detailed issues, in abilities and specific deficiencies. Knowing the measured physiological parameters is highly helpful in selecting the players and the types of practice given to them and eventually in the success of the coaches themselves.

2) According to the findings of this study, it is suggested to all water polo players to improve their skills by reducing their bodies' fat percentage and maintaining their desired muscular weights.

3) The finding of this research strongly suggestion to have a strength personal trainer for the water polo team.

\section{Further research suggestions}

1) The relationship between the anthropometric parameters and the anaerobic power of water polo players.

2) The relationship between the anthropometric parameters and the aerobic power of water polo players.

3) The comparison of the anthropometric parameters of water polo players in different positions and with their world's leading peers.

\section{Conflict of interest}

The author(s) declared no potential conflicts of interests with respect to the research, authorship, and/or publication of this article.

\section{Funding}

There was no grant or funding for this research and it was done by the personal budget of researchers.

\section{References}

1. Lozovina V, Pavicić L, Pavicic L. Anthropometric changes in elite male water polo players: survey in 1980 and 1995. Croat Med J 2004; 45(2): 202-205. (PMID: 15103759)

2. Tan FHY, Polglaze T, Dawson B, Cox G. Anthropometric and fitness characteristics of elite Australian female water polo players. J Strength Cond Res 2009; 23(5): 1530-1536. (doi: 10.1519/JSC.0b013e3181a39261) (PMID: 19620909)

3. Kondrič M, Uljević O, Gabrilo G, Kontić D, Sekulić D. General anthropometric and specific physical fitness profile of high-level junior water polo players. J Hum Kinet 2012; 32: 157-165. (doi: 10.2478/v10078-012-0032-6)

4. Sheppard JM, Cronin JB, Gabbett TJ, McGuigan MR, Etxebarria N, Newton RU. Relative Importance of Strength, Power, and Anthropometric Measures to Jump Performance of Elite Volleyball Players. J Strength Cond Res 2008; 22(3): 758-765. (doi: 10.1519/JSC.0b013e31816a8440)

5. Martínez JG, Vila MH, Ferragut $C$, Noguera MM, Abraldes JA, Rodríguez $\mathrm{N}$, et al. Position-Specific Anthropometry and Throwing Velocity of Elite Female Water Polo Players. J Strength Cond Res 2015; 29(2): $472-$ 477. (doi: 10.1519/JSC.0000000000000646)

6. Zampagni ML, Casino D, Benelli P, Visani A, Marcacci M, De Vito G. Anthropometric and strength variables to predict freestyle performance times in elite master swimmers. J strength Cond Res 2008; 22(4): 1298-1307. (PMID: 18545175)

7. Knechtle B, Baumann B, Knechtle P, Rosemann T. Speed during training and anthropometric measures in relation to race performance by male and female open-water ultra-endurance swimmers 1, 2 . Percept Mot Skills 2010; 111(2): 463-474. (doi: 10.2466/05.25.PMS.111.5.463-474)

8. McCluskey L, Lynskey S, Leung CK, Woodhouse D, Briffa K, Hopper D. Throwing velocity and jump height in female water polo players: Performance predictors. J Sci Med Sport 2010; 13(2): 236-240. (doi: 10.1016/j.jsams.2009.02.008)

9. Falk B, Lidor $\mathrm{R}$, Lander $\mathrm{Y}$, Lang $\mathrm{B}$. Talent identification and early development of elite water-polo players: a 2-year follow-up study. $J$ Sports Sci 2004; 22(4): 347-355. (doi: 10.1080/02640410310001641566)

10. Kamalden T, Nekooei P, Majlesi S. Physiological and biomechanical analyses of water polo goalkeepers. Greduc Upm Edu My 2013:692 697

11. Manning JM. Physiology of sport and exercise. Journal of Athletic Training 1999: 298-299. (PMID: 1322935)

12. Vaeyens $R$, Lenoir $M$, Williams AM, Philippaerts RM. Talent identificaton and development programmes in sport. Sports Med 2008; 38(9): 703-714. (doi: 10.2165/00007256-200838090-00001)

13. Hadavi F, Zarifi A. Talent identification and development model in Iranian athletics. World J Sport Sci 2009; 2(4): 248-253.

14. Williams AM, Reilly T. Talent identification and development in Indian football. J Sports Sci 2000; 18(9): 657-667. (doi: 10.1080/714004845)

15. Martínez JG, Vila MH, Ferragut C, Noguera MM, Abraldes JA, Rodríguez $\mathrm{N}$, et al. Position-specific anthropometry and throwing velocity of elite female water polo players. J Strength Cond Res 2015; 29(2): 472-477. (doi: 10.1519/JSC.0000000000000646)

16. Alcaraz PE, Abraldes JA, Ferragut $C$, Vila H, Rodríguez N, Argudo FM. Relationship between characteristics of water polo players and efficacy indices. J Strength Cond Res 2012; 26(7): 1852-1857. (doi: 10.1519/JSC.0b013e318237ea4f)

17. Vila Suárez $H$, Vila $H$, Ferragut $C$, Argudo F, Between R, Parameters A, et al. Relationship between anthropometric parameters and throwing velocity in water polo players. J Hum Sport Exerc 2009; 4(1): 57-68.

18. Shariat A, Kargarfard M, Danaee M, Bahri Mohd Tamrin S. Intensive resistance exercise and circadian salivary testosterone concentrations among young male recreational lifters. J Strength Cond Res 2015; 29(1): 151-158. (doi: 10.1519/JSC.0000000000000632)

19. Jabarouti R, Shariat A, Shariat A. Effect of Persian classic poetry on the level of stress hormone in retired academicians. J Poet Ther 2014; 27(1): 25-33. (doi: 10.1080/08893675.2014.871809)

20. Frenkl R, Mészáros J, Soliman A, Mohácsi J. Body composition and peak aerobic power in male international level Hungarian athletes. Acta Physiol Hung 2001; 88(3-4): 251-258. (PMID: 12162583) (doi: 10.1556/APhysiol.88.2001.3-4.7)

21. Avlonitou E. Energy requirements and training considerations in competitive water polo games. In: Proceedings of the Federation Internationale de Natation Amateur (FINA) First World Water Polo seminar Athens, Lausanne: FINA, 1991: 139-150.

22. Cazorla G, Montpetit RR. Metabolic and cardiac responses of swimmers, modern pentathletes, and water polo players during freestyle swimming to a maximum. Swim Sci V 1986 ;251-257.

23. Dlin RA, Dotan R, Inbar O, Rotstein A, Jacobs I, Karlsson J. Exaggerated systolic blood pressure response to exercise in a water polo team. Med Sci Sports Exerc 1984; 16(3): 294-298.

24. Carter L, Ackland T. Kinanthropometry in aquatic sports: a study of world class athletes. HK Sport Sci Monogr Ser 1994; (5): 23-41.

25. Smith JR, Norris J. The world encyclopedia of water polo. Olive Press Publications, 1989; $513 \mathrm{p}$.

26. Smith HK. Applied physiology of water polo. Sports Med 1998; 26(5): 317-334.

27. Wilmore J. Body composition in sport and exercise: directions for future research. Med Sci Sports Exerc 1982. 
28. Block J, Friedlander A, Brooks G, Steiger P, Stubbs H, Genant H. Determinants of bone density among athletes engaged in weightbearing and non-weight-bearing activity. J Appl Physiol 1989; 67(3): 1100-1105. (PMID: 2793702)

29. Lavoie JM, Montpetit RR. Applied physiology of swimming. Sport Med 1986; 3(3): 165-189. (PMID: 3520747)

30. Varamenti E, Platanou T. Comparison of anthropometrical, physiological and technical characteristics of elite senior and junior female water polo players: a pilot study. Open Sport Med J 2008; 2(1): 50-55. (doi: 10.2174/1874387000802010050)

31. Platanou T. On-water and dryland vertical jump in water polo players. $J$ Sports Med Phys Fitness 2005; 45(1): 26-31. (PMID: 16208287)

32. Ferragut $\mathrm{C}$, Abraldes J, Vila H, Rodríguez N, Argudo F, Fernandes R. Anthropometry and throwing velocity in elite water polo by specific playing positions. J Hum Kinet 2011; 27(1): 31-44. (doi: 10.2478/v10078-011-0003-3)

Authors:

Pooya Nekooei - PhD Candidates, Department of Physical Education and Sport Sciences, Faculty of Educational Studies, University Putra Malaysia, Selangor, Malaysia.

Sara Majlesi - PhD Candidates, Sport Center, University Malaya, Kuala Lumpur, Malaysia.

Gholamreza Sharifi - PhD, Head of Physical Education and Sport sciences Faculty, School of Physical Education and Sport Sciences, Khorasgan Branch, Islamic Azad University, Isfahan, Iran.

Tengku Fadilah Tengku Kamalden - PhD, Head of Sport Center Department, University Putra Malaysia, Selangor, Malaysia.

Paria Nekouei - PhD Condidates, Department of Exercise Physiology, Faculty of Physical Education and Sport Sciences, University of Isfahan, Isfahan, Iran. 